\title{
Nickel-Zirconia Anode Degradation and Triple Phase Boundary Quantification from Microstructural Analysis
}

\author{
A. Faes ${ }^{1,2 *}$, A. Hessler-Wyser ${ }^{2}$, D. Presvytes ${ }^{3}$, C. G. Vayenas ${ }^{3}$, J. Van herle ${ }^{1}$ \\ 1 Industrial Energy Systems Laboratory (LENI), Ecole Polytechnique Fédérale de Lausanne (EPFL), CH-1015 Lausanne, Switzerland \\ 2 Interdisciplinary Centre for Electron Microscopy (CIME), EPFL, CH-1015 Lausanne, Switzerland \\ 3 Department of Chemical Engineering, University of Patras and Institute of Chemical Engineering and High Temperature Chemical \\ Processes FORTH, GR-26504 Patras, Greece
}

Received November 4, 2008; accepted March 12, 2009

\begin{abstract}
Microstructural evolution of anode supported solid oxide fuel cells (SOFC) during medium-term stack testing has been characterised by scanning electron microscopy (SEM). Low acceleration voltage SEM imaging is used to separate the three anode phases (nickel, yttria-stabilised zirconia and porosity). Microstructural quantification is obtained using a software code that yields phase proportion, particle size, particle size distribution and a direct measure of triple phase boundary (TPB) density $\left(\mu \mathrm{m}^{-2}\right)$. In addition, an anode degradation model is proposed. The model describes the gradual degradation of the anode due to nickel particle sintering and the concomitant loss of TPB. Fundamental operational and
\end{abstract}

structural parameters of the anode can be used to estimate the TPB length change with time from the degradation rate. The combination of experimental results and modelling allows separating the degradation due to sintering of nickel particles from total stack degradation. Anode degradation occurs principally during the first 500 operating hours. For stack tests carried out over more than 1,000 h, anode degradation was responsible for 18 to $41 \%$ of the total degradation depending on initial microstructure.

Keywords: Image Processing, Nickel Particles Sintering, SOFC Degradation, TPB

\section{Introduction}

Solid oxide fuel cells (SOFC) constitute an energy conversion technology with great potential because of its high efficiency (electrical and cogeneration), modularity and fuel flexibility. Now that acceptable stack performances are reached [1], long-term stability is the main line of focus. When stacks in a power plant are installed, the output has to be calculated on the whole utilisation time. If degradation is too high, power limitation will rapidly occur and stacks will need to be oversized.

Degradation can be defined as drop in potential at constant current density during operating lifetime (expressed in $\mu \mathrm{V}$ per $\mathrm{h}$ ). The degradation is caused by all stack components and their interactions, especially from the following.

1. Interconnects:

- formation of a less-conductive oxide layer $[2,3]$

2. Cathode:

- densification of the structure [4]
- reaction with the zirconia electrolyte and formation of insulating pyrochlore (as lanthanum zirconate) or perovskite (as strontium zirconate) phases $[5,6]$

- reaction with volatile chromium species from the interconnect $[7,8]$

3. Electrolyte:

- loss of ionic conductivity due to phase changes, impurities and dopant diffusion [9-11]

4. Anode:

- coarsening of nickel particles [12-16]

- crack formation in the electrolyte during reoxidation of the anode support [3, 17-20]

- carburisation on nickel particles during internal reforming $[21,22]$

- formation of nickel sulphide when using unfiltered hydrocarbon fuel [23-25]

[*] Correspondingauthor, antonin.faes@epfl.ch 
Total stack degradation is the sum of these different contributions. The main challenge to understand and propose solutions to counter all these processes is to localise, separate and quantify them.

The coarsening of nickel particles is a reorganisation of the nickel phase in the yttria-stabilised zirconia (YSZ) backbone because of (i) high temperature exposure and (ii) surface tension between Ni and YSZ (the contact angle between YSZ and $\mathrm{Ni}$ is $117^{\circ}$ ) [26]. This increase in particle size will diminish the contact within the Ni phase (decrease in electronic conductivity) and also diminish the triple phase boundary (TPB) density (decrease in electrochemical activity). The TPB represents the line around which the electrochemical reaction occurs, with electrons in the Ni phase, oxygen anions from the YSZ phase and fuel and product molecules moving into the pores. If the TPB density or length (expressed in $\mu \mathrm{m} \mu \mathrm{m}^{-3}$ or $\mu \mathrm{m}^{-2}$ ) decreases, then some reaction volume disappears and the efficiency of the cell decreases.

Different groups used image treatment and analysis to study nickel coarsening in the SOFC anode. Simwonis et al. [13] worked on optical images, limiting the resolution to $0.35 \mu \mathrm{m}$. Several works used scanning electrical microscopy (SEM) [26-28]. Lee et al. [29] employed a combination of both SEM and optical microscopy images. Differences between those works and our approach will be commented in the experimental part.

Some theoretical approaches of anode degradation are proposed in the literature. Ioselevich et al. [12] used a percolation model with Monte Carlo simulation and effective medium theory [30]. Vassen et al. [15] extracted nickel diffusion from nickel coarsening.

In this paper, a method to measure TPB density, particle size, phase proportions and particle size distributions from SEM imaging is presented. An anode degradation model, featuring a simple approach regarding the time evolution of the $\mathrm{Ni}$ particle size is also included. Using this in combination with the Butler-Volmer equation, it links the time evolution of the TPB length with the degradation rate of the cell or stack as well as with fundamental (e.g. the anodic transfer coefficient $a$ ) and operational parameters of the cell or stack (e.g. temperature $T$ ).

\section{Experimental}

\subsection{Sample Preparation and Experimental Setup}

The $250 \mu \mathrm{m}$ thick anode supports were produced by tape-casting (HTceramix SA, Switzerland) using 55 wt.-\% $\mathrm{NiO}$ and 45 wt.-\% YSZ. Half cells were fabricated by co-sintering with a 5-10 $\mu \mathrm{m}$ thick 8YSZ electrolyte. For stacks A-C, lanthanum strontium ferrite (LSF) cathodes were deposited by screenprinting and sintering onto the 8YSZ electrolyte. The cells were tested in stack conditions (so-called R-design from HTceramix, [31]) using Fe26\%Cr interconnect from Plansee (so-called IT-10). Given the variability in production of sintered ceramics from small powder lots, in this study only those stacks (typically consisting of five cells each) were selected that included identical cells from a single tape casting + sintering batch (here ca. 30 cells, batch CY35A04). Stack D was based on more recent development: the LSF cathode was replaced by a composite of lanthanum strontium maganite (LSM) and YSZ, Crofer22APU replaced the Plansee interconnect and the anode support microstructure was modified to increase reoxidation resistance. To assess $\mathrm{Ni}$ grain growth with time in the anode, it was an aim to investigate stacks that had been operated for different durations. These criteria therefore limit the study to a few selected stacks. The emphasis here is on the employed methodology for anode microstructure quantification, and not on absolute stack performance and longevity.

The test durations and operating conditions of the selected stacks for this study are presented in Figure 1 and Table 1. The test reduction temperature was constant at $720^{\circ} \mathrm{C}$. Durability with the early generation cells (stacks A-C) has been poor, to a large extent because of interfacial reaction between LSF and YSZ [32] and Cr contamination of the cathode, as the FeCr metal interconnects, bore no air-side protective coating to suppress $\mathrm{Cr}$ evaporation [7, 8]. Nonetheless, temporal change of the anode microstructure (mostly nickel coarsening) is expected to contribute in stack performance loss, especially during relatively short operating periods soon after the high temperature reduction process, and it has been regarded here as an interesting challenge to quantify and separate this anode degradation process among other simultaneously occurring stack degradation processes.

A central piece of selected anode supports was extracted from tested cells (cell 4 for stack A, cell 5 for stack B, cell 3 for stack $C$, cell 1 for stack D). To preserve the microstructure during grinding, especially the small pores (down to tens of nanometres), the porous samples were impregnated using different mixtures of epoxy embedding kit (Fluka no. 45359) with acetone. The first impregnation was done in three volumes of acetone with one volume of epoxy, under mild vacuum (200 mbar) for $30 \mathrm{~min}$. The following steps were successive changes in the mixture composition as 1:1 (acetone/

Table 1 List of selected stack tests at LENI for anode microstructural analysis (HTceramix ${ }^{\circledR}$ early generation cells for stacks $A-C$ ). Air- $\lambda$ is the ratio between the air flow and the fuel flow.

\begin{tabular}{lcccc}
\multicolumn{1}{c}{ Stack } & A & B & C & D \\
\hline Test time (h) & 158 & 240 & 1,130 & 1,900 \\
Average current density $\left(\mathrm{A} \mathrm{cm}^{-2}\right)$ & 0.35 & 0.46 & 0.28 & 0.46 \\
Fuel flow $(97 \% \mathrm{H} 23 \% \mathrm{H} 2 \mathrm{O})$ & 6 & $5(0-100 \mathrm{~h})$ & $5(0-300 \mathrm{~h})$ & $7(0-1,000 \mathrm{~h})$ \\
$\left(\mathrm{mL} \mathrm{min}^{-1} \mathrm{~cm}^{-2}\right)$ & & $8(100-240 \mathrm{~h})$ & $6(300-1,130 \mathrm{~h})$ & $8(1,000-1,900 \mathrm{~h})$ \\
& 40 & 40 & $40(0-470 \mathrm{~h})$ & $40(0-300 \mathrm{~h}$ and \\
Fuel utilisation (FU) (\%) & & & $25(470-1,130 \mathrm{~h})$ & $1,000-1,900 \mathrm{~h})$ \\
& 1.6 & 1.6 & 1.6 & 2 \\
Air- $\lambda$ & -592 & -755 & -262 & -54
\end{tabular}



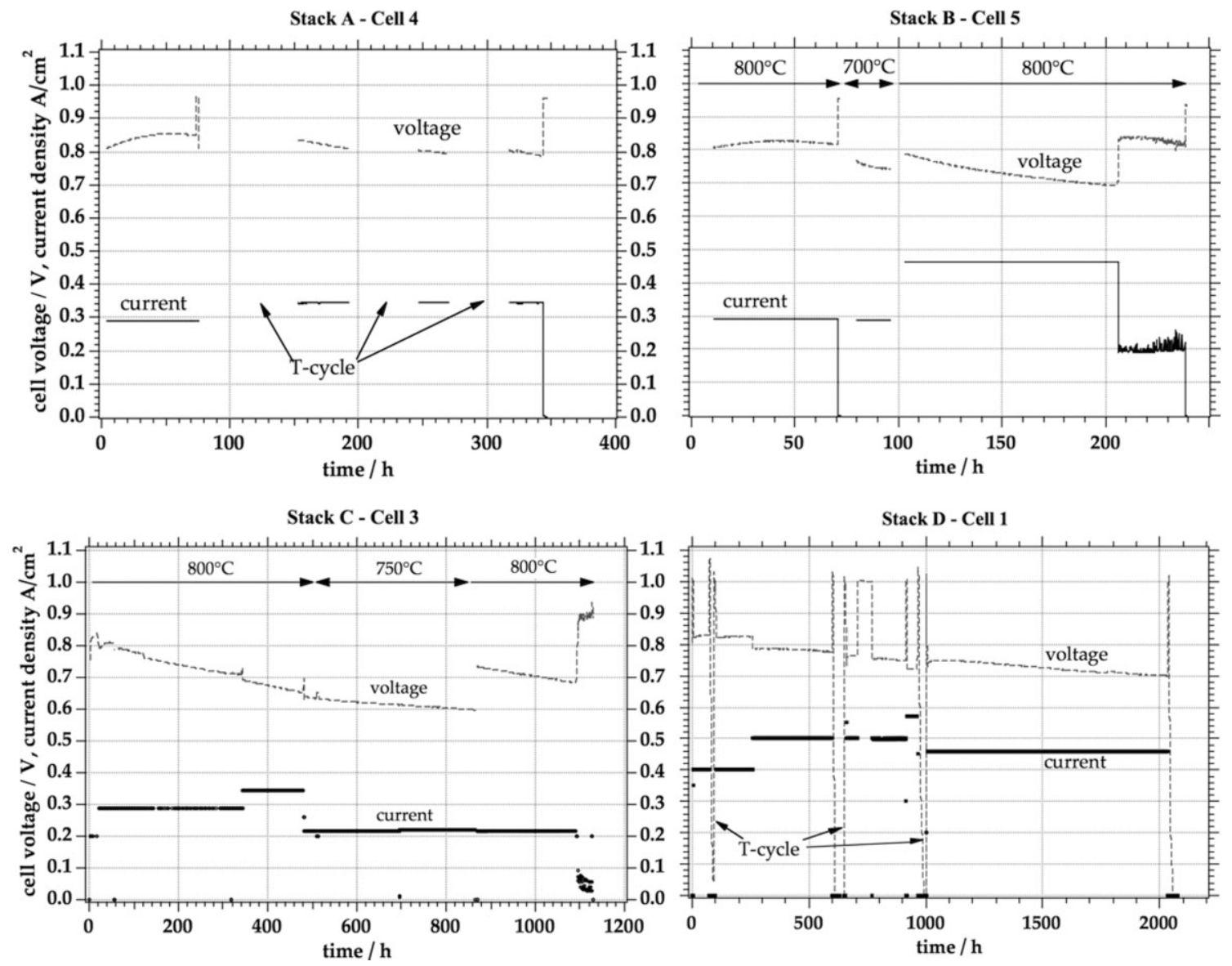

Fig. 1 Stack operating time and conditions (stacks $A$ and D were tested at $800{ }^{\circ} \mathrm{C}$ ).

resin), 1:3 and finally only epoxy [33]. The resin cure occurred for $24 \mathrm{~h}$ at $60{ }^{\circ} \mathrm{C}$. Samples were polished with diamond lapping films down to $0.1 \mu \mathrm{m}$, with water as cooling and lubrication medium.

A scanning electron microscope FEI XL-30 SFEG Sirion was used to take cross-section images at low acceleration voltage. As the back-scattered electron (BSE)-yield coefficients for nickel and YSZ are similar, high voltage and current density can be used to distinguish the phases [28]. Drawbacks of high voltage are first a lower resolution due to bigger interaction volume between electron and matter and then an overestimation of the denser phase (nickel). Other authors used an indirect technique to separate Ni, YSZ and pore phases. In that case information from the three phases came from different images [29, 34]. To limit the drawbacks of an indirect technique or high voltage SEM imaging, secondary electron (SE) imaging at a low accelerating voltage of $1 \mathrm{kV}$ was performed. These conditions were recently presented by Thydén et al. [35] and gave good contrast between nickel, yttria-stabilised zirconia and porosity (Figure 2). Identical working distance (5 mm), magnification $(2,000 \times)$ and high beam current density (spot size 4 and $50 \mu \mathrm{m}$ diaphragm) were fixed for the full batch of observations.
Light scattering particle size analyses were conducted on raw powder suspensions (in $0.1 \%$ polyacrylic acid solution of $\mathrm{pH}=10$ and dispersed with ultrasound horn for $15 \mathrm{~min}$ ) using a Mastersizer from Malvern Institute (UK).

Specific surface area measurements were performed with a Micrometrics Gemini 2376. Samples were dried for $1 \mathrm{~h}$ at $200{ }^{\circ} \mathrm{C}$ under nitrogen before measurement.

\subsection{Quantitative Image Analysis}

A Mathematica ${ }^{\circledR}$ code was developed in-house using the add-on Digital Image Processing (Wolfram) to treat and analyse the original images.

Image treatment consists in reducing the 256 grey levels from the original image to only 3 grey levels corresponding to the three phases (black for pores, grey for YSZ and white for Ni). This is achieved by applying two thresholds to the grey level histogram of the original image to first obtain two binary images corresponding to the nickel and pore phases [36]. The threshold values are defined by the difference from the peak centre to the darker minima. For the black-grey threshold, a value of $40 \%$ from the grey peak is used and for the grey-white threshold a value of $65 \%$ from the white peak is used. Cleaning of the binary images (to remove isolated 


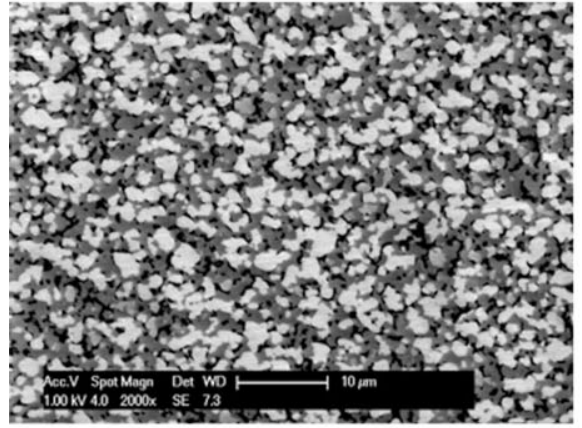

$$
\begin{aligned}
& \text { White }=\mathrm{Ni} \\
& \text { Grey }=\text { YSZ } \\
& \text { Black = Pore }
\end{aligned}
$$
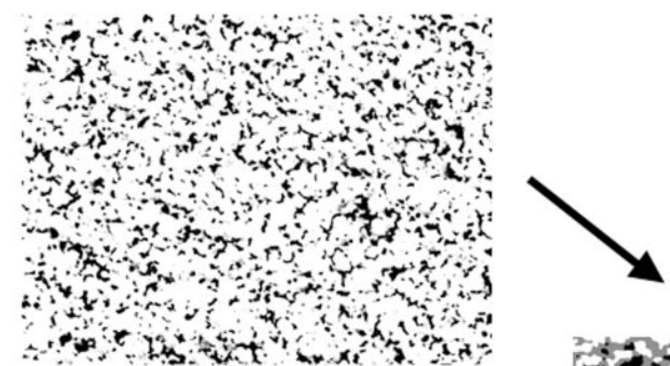

Grey Level Histogram
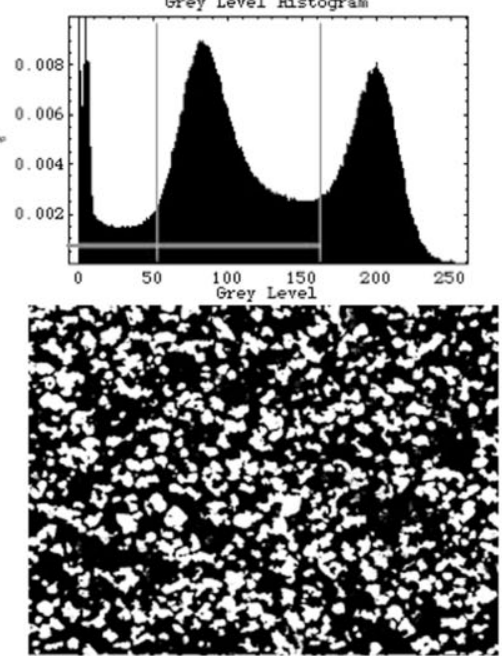

Fig. 2 Image treatment; double thresholding to obtain $\mathrm{Ni}$ (white, bottom figure in central column) and pore (black, top figure in central column) binary images; the arrows represent image cleaning (see text) and recombination to obtain the three phase images (YSZ = grey in the right most figure).

pixels) is then performed using morphological operations, such as 'opening' and 'closing' [37]. An 'opening' is composed of an erosion followed by a dilation, while a 'closing' is a dilation followed by an erosion. Erosion removes any pixel that has a background neighbour (black pixels). Conversely, dilation adds a white pixel layer around any white pixel surrounded by the background. The erosion order is defined as the number of consecutive erosions. Erosion and dilation are applied using a structuring element, in our case an octagon (after high order opening the structuring element shape can be observed, see Figure 3). These operations smooth irregular borders, and fill in or remove isolated pixels and lines. After cleaning these binary images, the recombination of pores (black) and nickel (white) images will render the grey YSZ phase (Figure 2). All treated images are finally compared to the original one.

Image analysis extracts quantitative microstructural information from the treated pictures (Figure 4).
- Volume fraction $\left(V_{i}\right)$ : measured from the surface fraction of the different phases $i$ as $\mathrm{Ni}, \mathrm{YSZ}$ and pores on the image. Volume fraction of the sample $\left(V_{V}\right)$ corresponds to surface fraction of the image $\left(A_{A}\right), V_{V}=A_{A}$. This is the basic relation for quantitative stereology [38].

- Particle size, 1st method $\left(l_{I M}\right)$ : using the intercept method (IM) $[28,39]$. The number of particles from the phase $i$ intercepted by the line $(N)$ is measured along horizontal and vertical lines (spaced of 10 pixels). Knowing the total length of the line $(L)$ and the volume fraction, the particle size can be obtained from:

$l_{I M, i}=\frac{L V_{i}}{N_{i}}$

To obtain the real mean particle size from the image analysis data, the value from the IM for nickel $\left(l_{I M, N i}\right)$ was multiplied by 1.5 as the Ni particles are considered spherical (as $l_{I M}=4 \frac{V}{S}=4 \frac{\pi d^{3} / 6}{\pi d^{2}}=\frac{2}{3} d$ then $\left.d=1.5 l_{I M}\right)$ [38]. According to
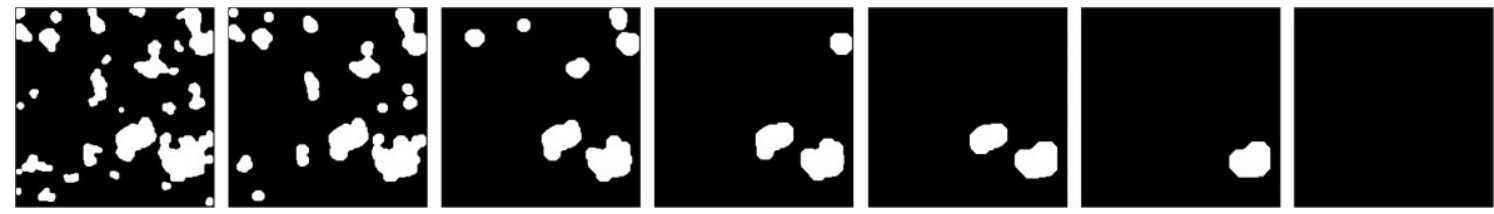

Fig. 3 Particle size distribution obtained by consecutive opening (with octagon as structuring element). 


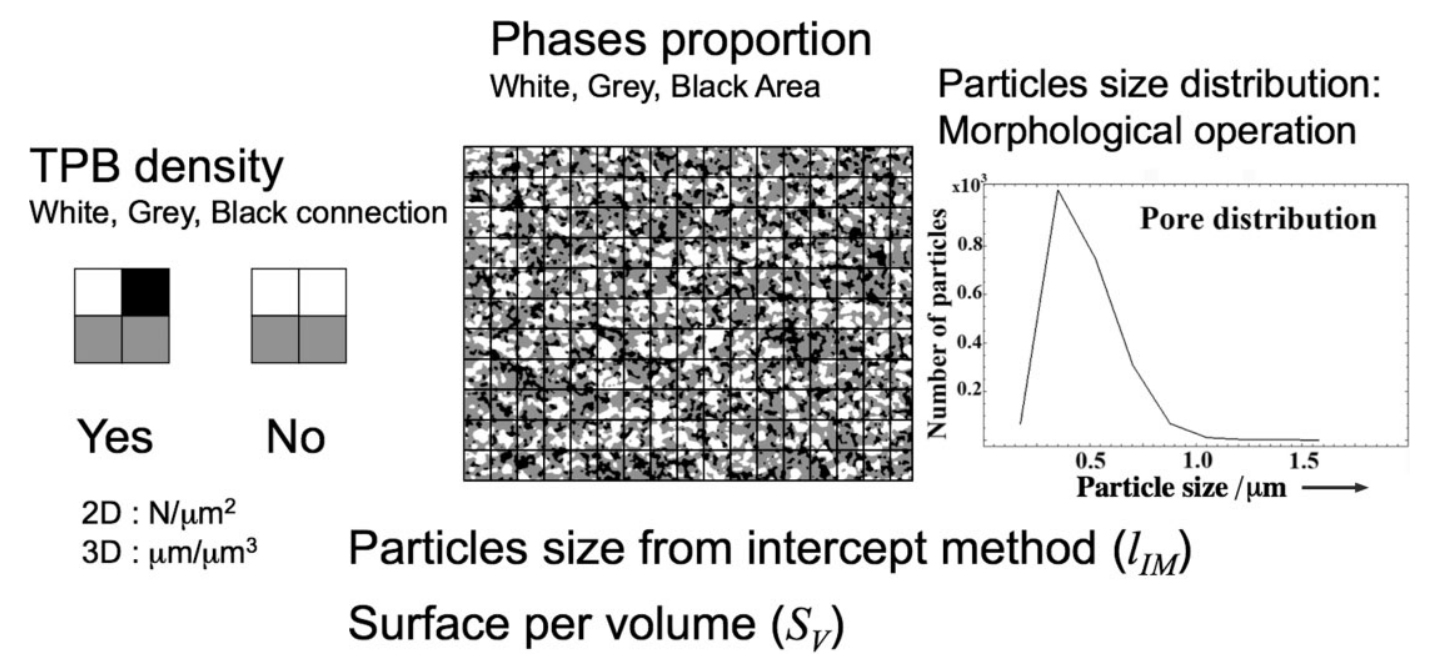

Fig. 4 Image analysis giving (1) phase proportion, (2) surface per volume, (3) particle size, (4) particle size distribution and (5) TPB density.

the ASTM standards [40] equiaxed but irregularly shaped grains should be multiplied by 1.13. That is the case for the YSZ and pore phases measured by the $\operatorname{IM}\left(l_{I M, Y S Z}\right.$ and $\left.l_{I M, p}\right)$.

- Particle size, 2 nd method $\left(l_{M O, i}\right)$ and particle size distribution: based on morphological operation (MO) [41, 42]. The size distribution of a complex microstructure is possible to derive by increasing the opening order step by step (Figure 3). After each step, a certain surface is lost, which can be related to the number of particles, knowing the single surface of a particle (defined by the structuring element and the step number). $l_{M O, i}$ is the mean size in number calculated from the number of particles per class interval $\left(N_{j}\right)$. At a magnification of $\times 2,000$ and with an octagon as structuring element, the class interval step is equal to $0.175 \mu \mathrm{m} . l_{M O, i}$ is the average of the distribution and it indicates the mean value; the dispersion or width of the distribution is described by its standard deviation $(\sigma)$ [43].

$l_{M O}=\frac{\sum_{j=1}^{n} N_{j} l_{j}}{N_{t o t}}$

$\sigma\left(l_{M O}\right)=\sqrt{\frac{\sum_{j=1}^{n} N_{j}\left(l_{j}-l_{M O}\right)^{2}}{N_{t o t}-1}}$

$l_{j}$ is the particle size of the class $\mathrm{j}$ and the total number of particles analysed is $N_{t o t}=\sum_{j=1}^{n} N_{j}$

- Surface per volume $\left(S_{V, i}\right)$ for the phase $i$ : the IM gives information about interfaces per volume (in $\mu \mathrm{m}^{2} \mu \mathrm{m}^{-3}$ or $\mu \mathrm{m}^{-1}$ ) present in the sample.

$S_{V, i}=\frac{N_{i}}{L}$
This calculation for the porosity phase $\left(S_{V, p}\right)$ can be related to specific surface area measurements.

- TPB density or TPB length $\left(l_{t p b}\right)$ : this is obtained by scanning the image with a $2 \times 2$ pixel matrix and comparing the pixel values (as shown in Figure 4 ) in this matrix. The number of TPB points (OD) in the image (2D) yields the TPB density in $\mu \mathrm{m} \mu \mathrm{m}^{-3}$ or $\mu \mathrm{m}^{-2}$. A factor 2 is introduced: the stereology calculus [38] gives that the length in a volume $\left(L_{V}\right)$ is equal to twice the number of points in a surface $\left(\mathrm{P}_{\mathrm{A}}\right), L_{V}=2 P_{A}$.

\section{Results and Discussion}

Stacks were tested in different conditions (see Figure 1). As temperature and current density were unfortunately not always constant, mean values were taken for the full tested time. Stack A was tested at $0.35 \mathrm{~A} \mathrm{~cm}^{-2}$ and underwent four thermal cycles, stack B was tested under higher current density $\left(0.46 \mathrm{~A} \mathrm{~cm}^{-2}\right)$ and stack $C$ under lower current density $\left(0.22-0.34 \mathrm{~A} \mathrm{~cm}^{-2}\right)$. The operating durations were 158, 240 and 1,130 h for stacks A, B and C, respectively. A mean degradation rate was derived from the initial potential to the final potential over the full time of utilisation and the results are presented in Table 1.

Two images were analysed on each sample. The outcome was always reproducible. Measurements were done close to and far away from the electrolyte to see if the morphological variation was different in the electrochemically active region and the bulk support. No difference was obtained between the anode support and the active region. It is recalled that after fabrication, the anode structure is homogeneous throughout, i.e. no anode functional layer is used. Figure 5 presents a micrograph of the samples and Table 2 presents the results of the full set of image analyses.

Phase proportions for the sample lay close to the theoretical values obtained from volume contraction of nickel oxide 

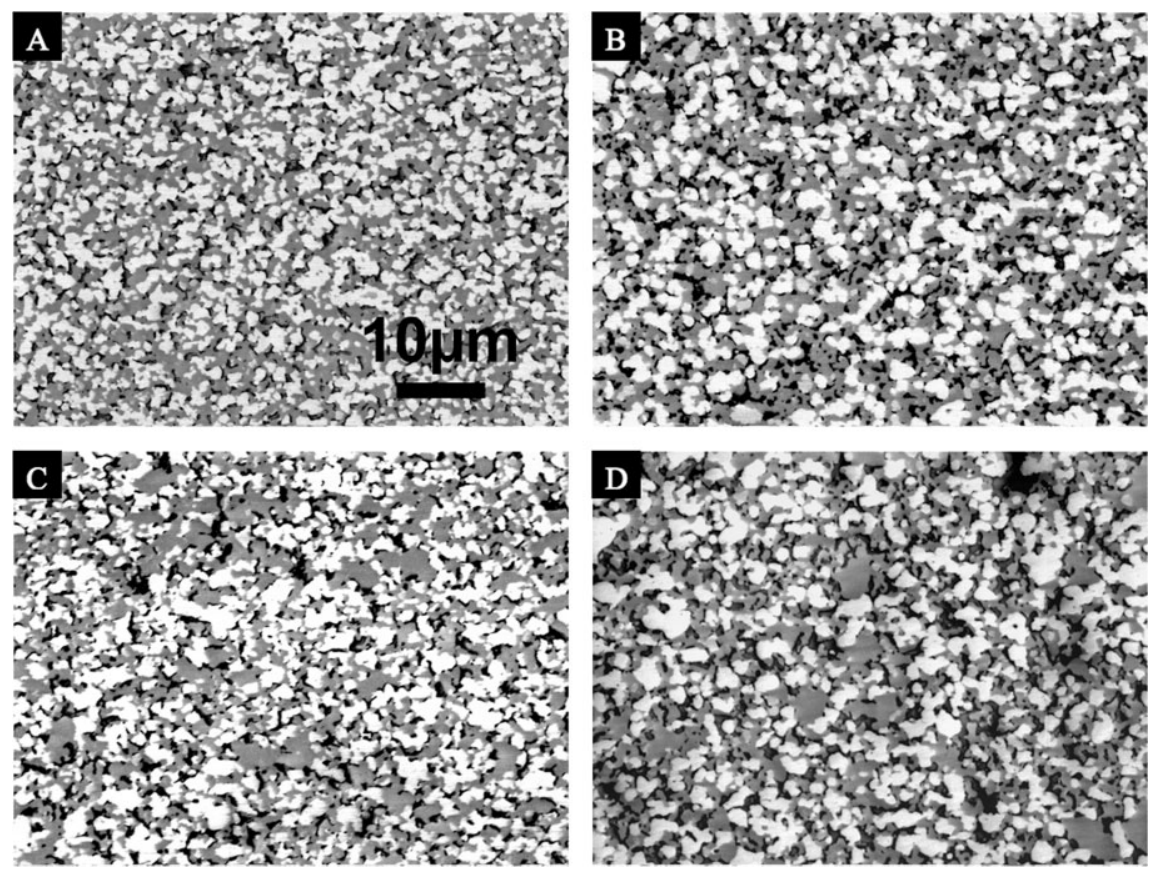

Fig. 5 SEM image at same magnification $(1,000 \times)$ of sample (a) zero time (standard anode), (b) stack C 1,130 h (standard anode), (c) zero time (modified anode) and (d) stack D 1,900 h (modified anode).

Table 2 Post test anode image analysis results for the stacks listed in Table 1.

\begin{tabular}{|c|c|c|c|c|c|c|}
\hline Sample & $\begin{array}{l}\text { Zero time } \\
\text { (reduced cell } \\
\text { from same } \\
\text { batch) }\end{array}$ & Stack A & Stack B & Stack C & Zero time & Stack D \\
\hline \multirow[t]{2}{*}{ Testing time (h) } & 0 & 158 & 240 & 1,130 & 0 & 1,900 \\
\hline & \multicolumn{6}{|c|}{ Phase proportion (\%) } \\
\hline Porosity & $19.5 \pm 2.0$ & $20.2 \pm 2.1$ & $19.0 \pm 1.9$ & $19.7 \pm 2.0$ & $19.8 \pm 2.0$ & $20.4 \pm 2.1$ \\
\hline YSZ & $50.3 \pm 5.1$ & $50 \pm 5.0$ & $50.5 \pm 5.1$ & $50.3 \pm 5.1$ & $49.6 \pm 5.0$ & $49.7 \pm 5.0$ \\
\hline \multirow[t]{2}{*}{$\mathrm{Ni}$} & $30.2 \pm 3.1$ & $29.8 \pm 3.0$ & $30.5 \pm 3.1$ & $30 \pm 3.0$ & $30.6 \pm 3.1$ & $29.9 \pm 3.0$ \\
\hline & \multicolumn{6}{|c|}{ Particle size, interception line method $\left(l_{I M, i}\right)(\mu \mathrm{m})$} \\
\hline Uncorrected porosity & 0.29 & 0.31 & 0.31 & 0.31 & 0.32 & 0.34 \\
\hline YSZ & 0.47 & 0.48 & 0.51 & 0.52 & 0.57 & 0.56 \\
\hline $\mathrm{Ni}$ & 0.42 & 0.51 & 0.54 & 0.57 & 0.52 & 0.60 \\
\hline Corrected porosity & $0.33 \pm 0.04$ & $0.35 \pm 0.04$ & $0.35 \pm 0.04$ & $0.35 \pm 0.04$ & $0.36 \pm 0.04$ & $0.38 \pm 0.04$ \\
\hline YSZ & $0.53 \pm 0.06$ & $0.54 \pm 0.06$ & $0.58 \pm 0.06$ & $0.59 \pm 0.06$ & $0.64 \pm 0.07$ & $0.63 \pm 0.07$ \\
\hline \multirow[t]{2}{*}{$\mathrm{Ni}$} & $0.63 \pm 0.07$ & $0.77 \pm 0.08$ & $0.81 \pm 0.09$ & $0.85 \pm 0.09$ & $0.78 \pm 0.08$ & $0.90 \pm 0.09$ \\
\hline & \multicolumn{6}{|c|}{ Particle size, MO method $\left(l_{M O, i}\right)(\mu \mathrm{m})$} \\
\hline Porosity & $0.47 \pm 0.16$ & $0.49 \pm 0.19$ & $0.54 \pm 0.18$ & $0.49 \pm 0.18$ & $0.51 \pm 0.19$ & $0.51 \pm 0.22$ \\
\hline YSZ & $0.53 \pm 0.27$ & $0.55 \pm 0.27$ & $0.57 \pm 0.29$ & $0.57 \pm 0.29$ & $0.61 \pm 0.36$ & $0.61 \pm 0.33$ \\
\hline $\mathrm{Ni}$ & $0.58 \pm 0.25$ & $0.67 \pm 0.31$ & $0.70 \pm 0.33$ & $0.73 \pm 0.35$ & $0.64 \pm 0.34$ & $0.75 \pm 0.38$ \\
\hline TPB density $\left(\mu \mathrm{m}^{-2}\right)$ & 1.84 & 1.50 & 1.44 & 1.38 & 1.68 & 1.34 \\
\hline
\end{tabular}

reduction to metallic nickel. The volume contraction is calculated from the molar volume (Table 3 ) and the equation $\Delta V_{\text {reduction }}=\left(V_{m, N i}-V_{m, N i O}\right) / V_{m, N i O}$. This gives a contraction of -41.7 vol.- $\%$ of the nickel oxide volume, corresponding to 21.8 vol.- $\%$ of final porosity if the original ceramics were fully dense. This result found confirmation from mercury porosimetry which gave $21 \pm 5$ vol.- $\%$ porosity after reduction of an anode support sample (batch
CY37A04, identical powders and preparation route as batch CY35A04 for stacks A-C).

Particle sizes presented in Table 2 are the result of the two particle size measuring methods. For qualitative observation see Figure 5.

Compared with the light diffraction diameter of the original YSZ and $\mathrm{NiO}$ powder $\left(d_{v 50}=0.39\right.$ and $0.52 \mu \mathrm{m}$, respectively), the analysis results show values of the same range. We have to take into account here that the $\mathrm{NiO}$ size increases in diameter during fabrication (sintering) of the cells, and then decreases in diameter during high temperature reduction of $\mathrm{NiO}$ to $\mathrm{Ni}$, which for a sphere can be approximated to $\frac{R_{N i}}{R_{N i O}}=\sqrt[3]{1-\Delta V_{\text {reduction }}}=0.835$. The specific powder surface area measurement using BET theory [44] with YSZ and $\mathrm{NiO}$ as starting powders yielded diameters $\left(d_{B E T}\right)$ of 0.14 and $0.21 \mu \mathrm{m}$, respectively. As the sintering of the cells occurs at high temperature, the particle sizes measured between raw powders and sintered anode will increase.

Particle size evolution with time is presented in Figure 6. The latter also compares the particle sizes resulting from the IM and MO method. Both techniques give similar values for the YSZ phase and are within error for the nickel phase. The pore size measurement from both methods presents a larger discrepancy because this phase shows the smallest size. The MO method is less sensitive to small particles (see Figure 4) as the images are cleaned with the same method and each step removes two layers of pixels (octagon as structuring element). In other words, smallest particles are confused with picture noise. To obtain a similar result for the pore phase with both techniques, the magnification should be increased beyond 2,000 times (the interval step is equal to $0.175 \mu \mathrm{m}$ at

Table 3 Nickel and nickel oxide molar mass, specific mass and molar volume [53].

\begin{tabular}{lcc} 
& $\mathrm{NiO}$ & $\mathrm{Ni}$ \\
\hline$M\left(\mathrm{~g} \mathrm{~mol}^{-1}\right)$ & 74.71 & 58.71 \\
$\rho\left(\mathrm{g} \mathrm{cm}^{-3}\right)$ & 6.67 & 8.9 \\
$V_{m}\left(\mathrm{~cm}^{3} \mathrm{~mol}^{-1}\right)$ & 11.32 & 6.60
\end{tabular}




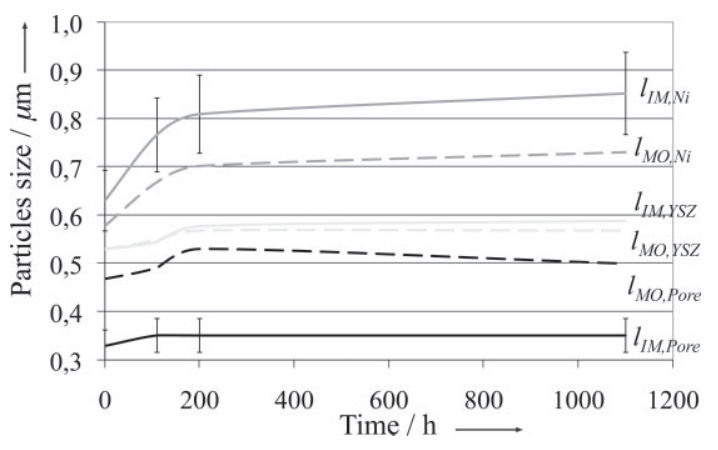

Fig. 6 Evolution of the particle sizes with time (stacks A-C). Dashed lines: particle size measured from consecutive opening method, $I_{M O}, i$. Solid lines: particle size measured from the intersection method, $\left.\right|_{1 M, i}$. Black lines are for pore size measurement, light grey for nickel particles and medium grey for YSZ particles.

a magnification of $\times 2,000$ and will be equal to $0.0875 \mu \mathrm{m}$ at $\times 4,000$ ).

Figure 6 shows that nickel particle size increases significantly during the first $200 \mathrm{~h}$. The other phases show an evolution of the microstructure too. This can be understood for the porosity but the zirconia microstructure should remain stable at these temperatures $\left(750-800{ }^{\circ} \mathrm{C}\right)$. The increase in YSZ particle size is within measurement error from the phase proportion. The coefficient of deviation for phase proportion, o $(V) /$ $V$, using the systematic point method is $10 \%$ as presented by Hilliard et al. [38]. The phase proportion $\left(V_{i}\right)$ calculated from image pixels corresponds to using a systematic point method. This error is propagated on $l_{I M, i}$ through Eq. (1). For the particle size derived from the MO method $\left(l_{M O, i}\right)$, the error in Table 2 is given by the standard deviation [Eq. (3)]. The standard deviation on the porosity and YSZ phases is constant with time but increases for the nickel phase. After analysis of the Ni particles histogram distribution, certain nickel particles increase significantly in size, which causes $l_{M O, i}$ and $\sigma\left(l_{M O, i}\right)$ to increase.

The specific surface area obtained from a BET measurement for a reduced half-cell (batch CY37A04) gave $S_{B E T}=0.67 \pm 0.02 \mathrm{~m}^{2} \mathrm{~g}^{-1}$. The interface of porosity per volume $\left(S_{V, p}\right)$ can be calculated knowing the density (measured by $\mathrm{Hg}$ porosimetry, $\rho=7.01 \pm 0.03 \mathrm{~g} \mathrm{~cm}^{-3}$ ) and the porosity of the sample (also measured by $\mathrm{Hg}$ porosimetry, $V p=21 \pm 5$ vol. $-\%$ ).

$S_{V, p}=S_{B E T} \rho \frac{V_{p}}{1-V_{p}}$

This calculation gives $1.25 \pm 0.28 \mu \mathrm{m}^{2} \mu \mathrm{m}^{-1}$. Image analysis and Eq. (4) were used to calculate $S_{V, p}$ from the freshly reduced anode support (CY35A04), leading to $1.35 \pm 0.14 \mu \mathrm{m}^{-1}$. These two results lie very close considering the error on the measurements. Furthermore, $S_{V, p}$ from image analysis is expected to be slightly bigger as mercury porosimetry does not measure closed porosity.
Usually, particle coarsening follows the Oswald ripening law [45]:

$(2 R)^{3}-\left(2 R_{0}\right)^{3}=k_{s, \text { Osw }} t$

or an exponential growth law [46], which can be derived from simple Ni mass balance considerations by assuming that the sintering process occurs at the contact area of adjacent $\mathrm{Ni}$ particles (see appendix A):

$R=R_{0} \exp \left(k_{s, E x p} t\right)$

where $R_{0}$ is the initial particle radius and $k_{s}$ the rate constant for the process. In Figure 7 only the measured values at $t=158 \mathrm{~h}$ (stack A) and $t=240 \mathrm{~h}$ (stack B) follow both laws. The value at $t=1,130 \mathrm{~h}$ (stack $\mathrm{C}$ ) then strongly deviates from both model predictions. The reason is believed to be that the zirconia backbone stops excessive nickel particle coarsening. Therefore, we introduced this limitation in an alternative model, as a maximal size that the nickel particles can reach (represented by $R_{\max }$ ). This suggested process is similar to the law obeyed by a charging capacitor:

$R=\left(R_{\max }-R_{0}\right)\left(1-\exp \left(-k_{s, \text { Cap }} t\right)\right)+R_{0}$
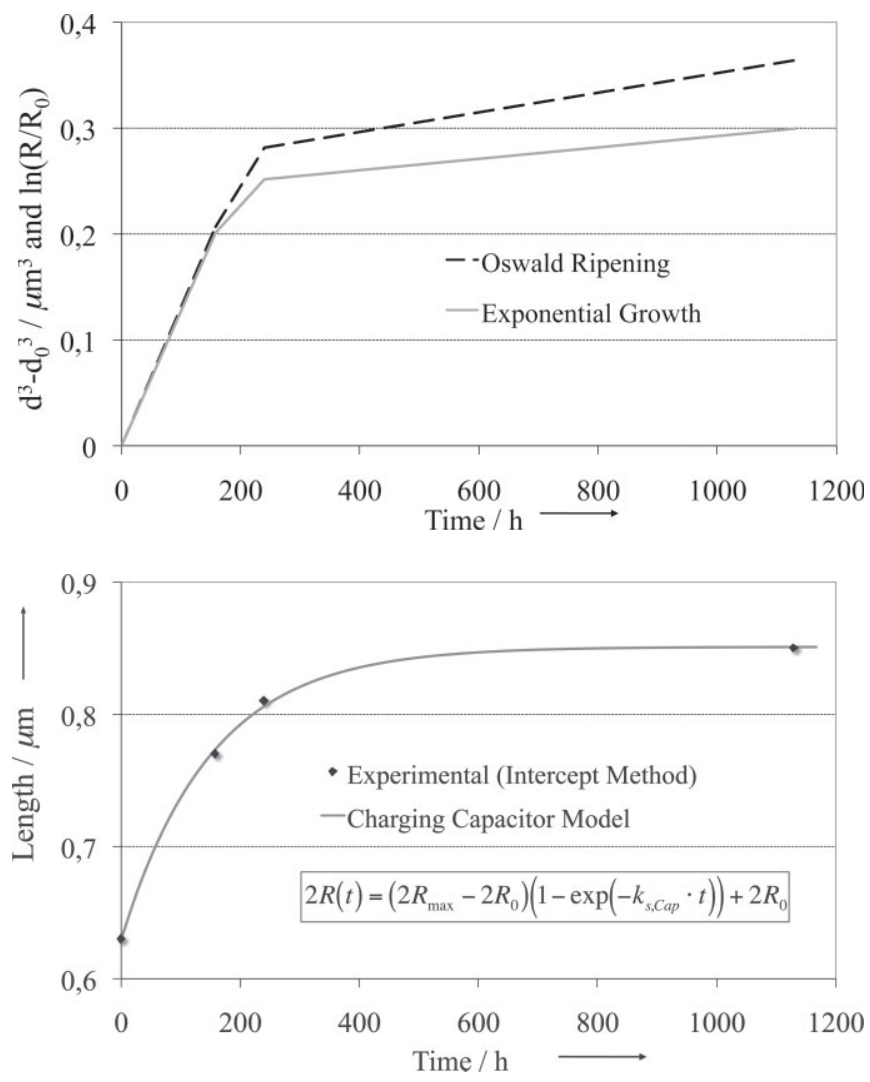

Fig. 7 Top: linearisation of the data $\left(\mathrm{I}_{\mathrm{IM}}\right)$ using the Ostwald ripening law and the Exponential growth law for nickel particles. Bottom: fit of the experimental $\left(\mathrm{I}_{\mathrm{IM}}\right)$ data with a charging capacitor model. 
Here $1 / k_{s, \text { Cap }}=\tau$, where $\tau$ is a time constant for nickel coarsening. The rate constants $k_{s}$ for the different models (Oswald ripening, $k_{s, O s w}$; exponential growth, $k_{s, \text { Exp }}$; charging capacitor, $\left.k_{s, \text { Cap }}\right)$ are presented in Table 4 . In Figure 7 we see that the charging capacitor model fits well with the experimental data. The maximal radius is close to the value obtained at $1,130 \mathrm{~h}$. The time constant is around $160 \mathrm{~h}$ $\left(151 \pm 8 \mathrm{~h}\right.$ for $l_{I M}$ and $163 \pm 11 \mathrm{~h}$ for $\left.l_{M O}\right)$, which corresponds to a period during which the microstructure changes rapidly and where the two classical models (Ostwald ripening and exponential growth) also approximate the nickel particle growth. After this period the nickel coarsening is slowly stopped by the YSZ skeleton.

After $600 \mathrm{~h}$, the nickel particle size seems to be constant (Figure 7) and the diameter at 'infinite' time is only $0.1 \%$ bigger than after $1,130 \mathrm{~h}$. This makes it possible to compare data from the literature when the utilisation time is over 600 h. Table 5 compares nickel coarsening data in Ni/YSZ anode supports. The interesting point is that all the data lie in the same range, between 15 to $34 \%$ increase in the Ni particle size for all anode supports. The literature for Ni coarsening in anodes on electrolyte supported cells reports huge coarsening of the nickel phase up to 130\% [47]. No clear tendency is observed between nickel coarsening and time of utilisation or temperature of the test. The extreme values are for stack $C$ and $D$ in this study. The difference in anode from stack $C$ to $D$ is a change in the original microstructure, both $\mathrm{Ni}$ and YSZ particles were increased in starting size by 21 and $24 \%$, respectively. The pore size is approximately constant between the two anode microstructures. To obtain a more stable anode, its microstructure needs to be coarser.

As the nickel particle size increases, the TPB density diminishes from $1.84 \mu \mathrm{m}$ originally to $1.38 \mu \mathrm{m}$ after $1,130 \mathrm{~h}$ (see Table 2). This decrease can be well fitted with an equivalent unloading capacitor model $l_{t p b}(t)=l_{t p b, \infty}+\left(l_{t p b, 0}-l_{t p b, \infty}\right)$ $\exp \left(-k_{s, \text { Cap }} t\right)$ (Figure 8), the time constant is $118 \mathrm{~h}$ in this case.

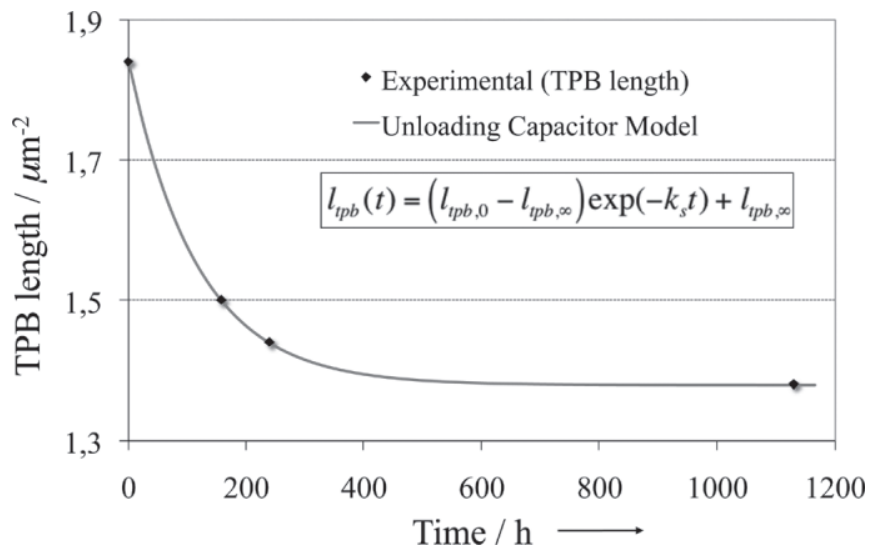

Fig. 8 Fit of the experimental (Itpb) data with a unloading capacitor model.

The original TPB density obtained here is of the same order as the value obtained by Wilson et al. [48] $\left(l_{t p b, W i l s o n}\right.$

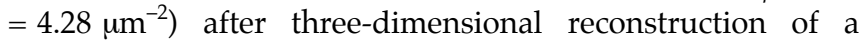
$\mathrm{Ni} /$ YSZ anode functional layer (AFL). The difference can be explained by the fact that the anode support tested here did not contain any AFL. Here the anode support fulfills two functions: the mechanical strength is given by the coarse YSZ skeleton and the electrochemical activity is mainly given by the TPB density. This compromise decreases the TPB density.

\subsection{Anode Degradation Model for Particle Coarsening and Sintering}

Using fundamental electrochemical equations, one can link the time evolution of the TPB length $\left(l_{t p b}\right)$ with structural and operational parameters of the anode.

We consider the high field approximation of the ButlerVolmer equation $[49,50]$, which relates current with the overpotential $(\eta)$,

$i=i_{0} \exp \left(\frac{a F \eta}{R T}\right) \Rightarrow \ln \left(\frac{i}{i_{0}}\right)=\frac{a F \eta}{R T}$

where $F$, the Faraday constant, $a$, the transfer coefficient (assumed as $0.5[49,50]), T$, the temperature, $i_{0}$, the exchange current density and $R$, the gas conTable 4 Time constants for the different models (using stack A and B for Oswald and exponential model, stack A-C for the capacitor model).

\begin{tabular}{lccccc} 
Method & $\mathrm{k}_{\mathrm{s}, \text { Osw }}\left(\mu \mathrm{m}^{3} \mathrm{~s}^{-1}\right)$ & $\mathrm{k}_{\mathrm{s}, \operatorname{Exp}}\left(\mathrm{s}^{-1}\right)$ & $\mathrm{k}_{\mathrm{s}, \mathrm{Cap}}\left(\mathrm{s}^{-1}\right)$ & $2 \mathrm{R}_{\max }(\mu \mathrm{m})$ & $\tau(\mathrm{h})$ \\
\hline$l_{I M}$ & $3.31 \times 10^{-7}$ & $2.99 \times 10^{-7}$ & $1.84 \pm 0.27 \times 10^{-6}$ & $0.851 \pm 0.004$ & $151 \pm 8$ \\
$l_{M O}$ & $1.73 \times 10^{-7}$ & $2.22 \times 10^{-7}$ & $1.70 \pm 0.41 \times 10^{-6}$ & $0.731 \pm 0.004$ & $163 \pm 11$
\end{tabular}

Table 5 Comparison of nickel coarsening in Ni/YSZ anode support.

\begin{tabular}{lccc} 
Operating conditions & Image analysis & $\begin{array}{c}\text { Ni particle size } \\
\text { increase (\%) }\end{array}$ & Source \\
\hline $1,500 \mathrm{~h}, 750{ }^{\circ} \mathrm{C}$ & IM & 30 & Hagen et al. [27] \\
$1,500 \mathrm{~h}, 850{ }^{\circ} \mathrm{C}$ & IM & 22 & Hagen et al. [27] \\
$4,000 \mathrm{~h}, 1,000{ }^{\circ} \mathrm{C}$ & $\mathrm{IM}$ & 26 & Simvonis et al. [13] \\
$600 \mathrm{~h}, 800{ }^{\circ} \mathrm{C}$ & $\mathrm{IM}$ & 29 & Monachon et al. [28] \\
$1,130 \mathrm{~h}, 800{ }^{\circ} \mathrm{C}$ & $\mathrm{IM}$ & $34 \pm 7$ & This study \\
$($ Stack C) & $\mathrm{MO}$ & $26 \pm 5$ & This study \\
$1,900 \mathrm{~h}, 800{ }^{\circ} \mathrm{C}$ & IM & $15 \pm 3$ & \\
$($ Stack D) & MO & $17 \pm 3$ &
\end{tabular}
stant. It should be noted that although the linear rather than the exponential (Tafel) approximation of the Butler-Volmer equation is frequently used in high temperature SOFC modelling, the linear approximation requires that $\frac{F \eta}{R T}<0.1$, thus $\eta<10 \mathrm{mV}$, which is not a realistic assumption even for very efficient anodes. For fixed current density $i$, one obtains via time differentiation:

$$
\begin{aligned}
-d \ln \left(i_{0}\right) & =\frac{a F}{R T} d \eta=\frac{a F}{R T}\left(\frac{d \eta}{d t}\right) d t \approx \frac{a F}{R T}\left(\frac{\mathrm{D} \eta}{\mathrm{D} t}\right) d t \\
& =-\frac{a F}{R T}\left(\frac{\mathrm{D} U}{\mathrm{D} t}\right) d t
\end{aligned}
$$


where $U$ is the cell potential and $D U / D t$ is the measurable degradation rate. Denoting by $U_{0}$ the open circuit voltage, $U=U_{0}-\eta$, then $\mathrm{D} \eta=-\mathrm{D} U$, as used in Eq. (10). One thus obtains by integrating Eq. (10):

$\ln \left(i_{0} / i_{0}^{0}\right)=\frac{a F}{R T}\left(\frac{\mathrm{D} U}{\mathrm{D} t}\right) t$

Eq. (11) shows the dependence of the experimentally measurable degradation rate $\mathrm{DU} / \mathrm{D} t$ on the exchange current density. The exchange current density, $i_{0}$, is proportional to the length of the three phase boundaries $[49,50]$, i.e.

$\ln \left(i_{0} / i_{0}^{0}\right)=\ln \left(\ell_{t p b} / \ell_{t p b, 0}\right)$

where $i_{0}{ }^{0}$, the initial exchange current density and $l_{t p b, 0}$, the initial TPB length.

Substituting Eq. (12) for Eq. (11), we obtain:

$\ell_{t p b}=\ell_{t p b, 0} \exp \left(\frac{a F}{R T}\left(\frac{\mathrm{D} U}{\mathrm{D} t}\right) t\right)$

Thus rewriting Eq. (13) as

$\frac{\mathrm{DU}}{\mathrm{D} t}=\frac{R T}{a F t} \ln \left(\ell_{t p b} / \ell_{t p b, 0}\right)$

one can predict the degradation rate on the basis of the time evolution of the TPB length. In doing this one assumes that the loss of TPB length is the only cause of anode degradation and that the anode degrades in a uniform manner. The latter is supported by the SEM images (Figure 5).

Table 6 compares the anode degradation rate calculated from Eq. (14) with the total stack degradation rate. One observes that the anode degradation due to nickel coarsening is quite significant and can exceed half of the initial stack degradation rate. These values obviously strongly depend on the a value used in the Butler-Volmer equation and on the accuracy of the TPB length estimates. More data will be needed for a more quantitative comparison.

The TPB length is also stabilising with time as presented in Figure 8. From this figure and Eq. (14), it is possible to extrapolate the anode degradation for any time.

The proportion of the degradation coming from the anode is more important at the beginning of the test as presented in Table 6 . After $158 \mathrm{~h}$ the anode degradation represents $40 \%$ of total degradation, after $1,130 \mathrm{~h}$ it is only $18 \%$ of total degradation. As nickel particle coarsening occurs during the begin-

Table 6 Comparison of degradation calculated for the anode and observed on the full stack.

\begin{tabular}{|c|c|c|c|c|}
\hline & Stack A & Stack B & Stack C & Stack D \\
\hline Degradation from $l_{t p b}$ [Eq. (14)] $\left(\mu \mathrm{V} \mathrm{h}^{-1}\right)$ & -239 & -189 & -47.1 & -22.0 \\
\hline Cell degradation (experimental) $\left(u V h^{-1}\right)$ & -592 & -755 & -262 & -54.0 \\
\hline $\begin{array}{l}\text { Proportion of anode degradation on } \\
\text { total degradation }(\%)\end{array}$ & 40 & 25 & 18 & 41 \\
\hline
\end{tabular}

ning of the test (time constant $\approx 160 \mathrm{~h}$ ) initial degradation is mainly due to the change in anode microstructure. Long-term degradation is principally coming from the cathode side, as lanthanum zirconate formation causes cathode detachment from the electrolyte [27] and as chromium poisoning from volatile $\mathrm{Cr}$ species emanating from the interconnect affects the reaction at the cathode TPB [8].

The degradation proportion in stack $\mathrm{D}$ due to the anode is more important than in stack $C$ even if the stack $C$ lifetime was shorter. However, in absolute values, the anode degradation from stack D is more than twice as small as the one from stack C. Stack D, as mentioned, comes from a more recent development using (i) a different cathode composition (LSM/ YSZ replaces the LSF); (ii) another interconnect and (iii) especially, a coarser anode microstructure, with total stack degradation reduced by a factor of 5 compared to the early stacks. As the other cell components were greatly improved, the proportion of anode degradation increases even if the absolute value decreased. Long-term stable anodes can be designed by coarsening the original Ni/YSZ microstructure or maybe by using a ceramic anode [51].

In this paper the emphasis was on the employed methodology for anode microstructure quantification, and not on absolute stack performance. As stacks were tested for different research purposes, temperature and current density were not always constant. Therefore, a mean value for temperature and current density had to be approximated for the full test time in this study. A more recent study using dedicated electrochemical tests of small active area is presented by Tanasini et al. [52] to exclude or limit stack degradation source such as chromium poisoning, fuel starvation and anode edge reoxidation. A parallel microstructural degradation study of both electrodes was undertaken there to understand and isolate their principal mechanisms.

\section{Conclusion}

HTceramix anode supported cells were tested in real stack conditions. Direct microstructural quantification of the tested SOFC anodes was performed using SEM imaging under low accelerating voltage. Image treatment and analysis was carried out with a software code to give information on the phase proportions, particle sizes from the IM, particle sizes and particle size distribution from a MO method, as well as a direct measurement of TPB density. An alternative model to Oswald ripening or exponential growth was presented to describe the nickel coarsening in the YSZ structure. This indicates that the sintering of $\mathrm{Ni}$ is acting mostly during the first $500 \mathrm{~h}(\approx 3 \tau)$ of stack operation.

A second model linked the TPB length variation, which is another way to measure nickel coarsening, to the degradation rate. Based on TPB quantification, this model gave the portion of stack degradation corresponding to anode performance decrease due to particle sintering. This proportion can be up to $40 \%$ of initial stack degradation. 


\section{Acknowledgements}

Kind acknowledgements are extended to the European Institute for Energy Research (EIfER, Karlsruhe, Germany, contract no. N43/C06/019) for financial support, to HTceramix ${ }^{\circledR}$ SA (Switzerland) for the material supply and to Professor Pierre Stadelmann (CIME, EPFL) for the constructive advice on image analysis. Thanks are due to the EPFL Powder Technology Laboratory for particle size distribution measurements and to EMPA, Switzerland, for the mercury porosimetry measurements. C.G. and D.P. duly acknowledge financial support received from the EU FP6 project 'RealSOFC' (SES6-502612) for the modelling work.

\section{Appendix}

Here we derive Eq. (7). Assuming an average initial radius $R_{0}$ for the Ni particles and an average radius $R$ after time $t$, one has the following equations for the TPB length $\left(l_{t p b}\right)$, surface area $(S)$ and volume $(V)$ in terms of the number of particles $(N)$ in the anode. The latter is also expected to decrease during the sintering process due to the disappearance of smaller particles.

$\ell_{t p b, 0}=2 \pi N_{0} R_{0} ; \ell_{t p b}=2 \pi N R$

$S_{0}=2 \pi N_{0} R_{0}^{2} ; S=2 \pi N R^{2}$

$V_{0}=\frac{2}{3} \pi N_{0} R_{0}^{3} ; V=\frac{2}{3} \pi N R^{3}$

Mass balance of the $\mathrm{Ni}$ atoms at constant density requires $V=V_{0}$, thus:

$\frac{N}{N_{0}}=\frac{R_{0}^{3}}{R}$

Therefore, from Eq. (15)-(18) one obtains:

$\frac{S}{S_{0}}=\frac{R_{0}}{R}$

$\frac{\ell_{t p b}}{\ell_{t p b, 0}}=\frac{R_{0}^{2}}{R^{2}}$

Assuming that the rate of sintering is proportional to the contact area, $S_{c}$, of adjacent $\mathrm{Ni}$ particles, i.e.

$-\frac{d S}{d t}=k S_{c}$

and that $S_{c}$ is proportional to $S$, i.e. $S_{c}=b S$ (with $b$, a constant), as long as the spherical Ni particle assumption remains valid, and as long as $R$ does not reach the maximum value defined by the voids of the YSZ structure, then:

$\frac{d S}{d t}=-(k b) S$
$\left(S / S_{0}\right)=\exp (-k b t)$

Using Eq. (19),

$R=R_{0} \exp (k b t)$

which corresponds to the exponential growth model where $k_{s}$ $=k b[$ Eq. (7)].

\section{List of Symbols}

$V_{i} \quad$ volume fraction of the phase $i$

$A_{A} \quad$ surface fraction of the image

$l_{I M} \quad$ particle size from intercept method (IM) $(\mu \mathrm{m})$

$l_{M O} \quad$ particle size from morphological operation (MO)

$(\mu \mathrm{m})$

$N \quad$ number of particles

$\sigma \quad$ standard deviation

$S_{V} \quad$ surface per volume $\left(\mu \mathrm{m}^{-1}\right)$

$l_{t p b} \quad$ TPB density or TPB length $\left(\mu \mathrm{m}^{-2}\right)$

$S_{B E T} \quad$ specific surface area from BET $\left(\mathrm{m}^{2} \mathrm{~g}^{-1}\right)$

$k_{s} \quad$ rate constant for the process $\left(/ \mathrm{h}^{-1}\right)$

$R_{0} \quad$ initial particle radius $(\mu \mathrm{m})$

$R_{\text {max }} \quad$ maximal particle radius $(\mu \mathrm{m})$

$t \quad$ time (h)

$\tau \quad$ time constant for nickel coarsening (h)

a transfer coefficient

F $\quad$ Faraday constant $\left(\mathrm{C} \mathrm{mol}^{-1}\right)$

$T$ temperature (K)

$i_{0} \quad$ exchange current density / $\mathrm{A}\left(\mathrm{cm}^{-2}\right)$

$R \quad$ gas constant $\left(\mathrm{J} \mathrm{K}^{-1} \mathrm{~mol}^{-1}\right)$

$U \quad$ cell potential $(\mathrm{V})$

$\Delta U / \Delta t \quad$ measurable degradation rate $\left(\mu \mathrm{V} \mathrm{h}^{-1}\right)$

$U_{0} \quad$ open circuit voltage $(\mathrm{V})$

$S_{c} \quad$ contact area $\left(\mu \mathrm{m}^{2}\right)$

$M \quad$ molar mass $\left(\mathrm{g} \mathrm{mol}^{-1}\right)$

$\rho \quad$ specific mass $\left(\mathrm{g} \mathrm{cm}^{-3}\right)$

$V_{m} \quad$ molar volume $\left(\mathrm{cm}^{3} \mathrm{~mol}^{-1}\right)$

\section{Subscripts}

$p \quad$ porosity

$\mathrm{Ni} \quad$ Nickel

YSZ Yttria-stabilised zirconia

Osw Oswald ripening model

Exp exponential growth model

Cap charging capacitor model

IM intercept method

MO morphological operation

\section{References}

[1] M. Molinelli, D. Larrain, N. Autissier, R. Ihringer, J. Sfeir, N. Badel, O. Bucheli, J. Van Herle, J. Power Sources 2006, 154, 394. 
[2] Z. Yang, K. S. Weil, D. M. Paxton, J. W. Stevenson, J. Electrochem. Soc. 2003, 150, A1090.

[3] D. Larrain, J. Van herle, D. Favrat, J. Power Sources 2006, 161, 392.

[4] M. J. Joergensen, P. Holtappels, C. C. Appel, J. App. Electrochem. 2000, 30, 411.

[5] H. Yokokawa, N. Sakai, T. Kawada, M. Dokiya, Solid State Ionics 1990, 40, 398.

[6] H. Y. Lee, S. M. Oh, Solid State Ionics 1996, 90, 133.

[7] S. Taniguchi, M. Kadowaki, H. Kawamura, T. Yasuo, Y. Akiyama, Y. Miyake, T. Saitoh, J. Power Sources 1995, $55,73$.

[8] H. Yokokawa, T. Horita, N. Sakai, K. Yamaji, M. E. Brito, Y. P. Xiong, H. Kishimoto, Solid State Ionics 2006, $177,3193$.

[9] M. Hattori, Y. Takeda, Y. Sakaki, A. Nakanishi, S. Ohara, K. Mukai, J. H. Lee, T. Fukui, J. Power Sources 2004, 126, 23.

[10] J. Van herle, R. Vasquez, J. Eur. Ceram. Soc. 2004, 24, 1177.

[11] C. Haering, A. Roosen, H. Schichl, Solid State Ionics 2005, 176, 253.

[12] A. Ioselevich, A. A. Kornyshev, W. Lehnert, J. Electrochem. Soc. 1997, 144, 3010.

[13] D. Simwonis, F. Tietz, D. Stoever, Solid State Ionics 2000, 132, 241.

[14] S. Primdahl, M. Mogensen, J. Appl. Electrochem. 2000, 30, 247.

[15] R. Vassen, D. Simwonis, D. Stoever, J. Mater. Sci. 2001, $36,147$.

[16] H. Tu, U. Stimming, J. Power Sources 2004, 127, 284.

[17] M. Cassidy, G. Lindsay, K. Kendall, J. Power Sources 1996, 61, 189.

[18] T. Klemensoe, Ph.D. Thesis, Technical University of Danemark, Risoe National Laboratory, Topsoe Fuel Cell, 2005.

[19] D. Sarantaridis, A. Atkinson, Fuel Cells 2007, 7, 246.

[20] Z. Wuillemin, N. Autissier, M. Nakajo, M. Luong, J. Van herle, D. Favrat, J. Fuel Cell Sci. Technol. 2008, 5, 0110161.

[21] E. P. Murray, T. Tsai, S. A. Barnett, Nature 1999, 400, 649.

[22] K. Sasaki, K. Watanabe, K. Shiosaki, K. Susuki, Y. Teraoka, J. Electroceram. 2004, 13, 669.

[23] N. U. Pujare, K. W. Semkow, A. F. Sammells, J. Electrochem. Soc. 1987, 134, 2639.

[24] Y. Matsuzaki, I. Yasuda, Solid State Ionics 2000, 132, 261.

[25] S. Zha, Z. Cheng, M. Liu, J. Electrochem. Soc. 2007, 154, B201.

[26] S. P. Jiang, J. Mater. Sci. 2003, 38, 3775.

[27] A. Hagen, R. Barfod, P. V. Hendriksen, Y. L. Liu, S. Ramousse, J. Electrochem. Soc. 2006, 153, A1165.

[28] C. Monachon, A. H.-Wyser, A. Faes, J. Van herle, E. Tagliaferri, J. Am. Ceram. Soc. 2008, 91, 3405.

[29] J. H. Lee, H. Moon, H. W. Lee, J. Kim, J. D. Kim, K. H. Yoon, Solid State Ionics 2002, 148, 15.
[30] A. Ioselevich, A. A. Kornyshev, W. Lehnert, Solid State Ionics 1999, 124, 221.

[31] J. Van herle, D. Perednis, K. Nakamura, S. Diethelm, M. Zahid, A. Aslanides, T. Somekawa, Y. Baba, K. Horiuchi, Y. Matsuzaki, M. Yoshimoto, O. Bucheli, J. Power Sources 2008, 182, 389.

[32] S. Diethelm, J. Van herle, Z. Wuillemin, A. Nakajo, N. Autissier, M. Molinelli, J. Fuel Cell Sci. Technol. 2008, 5, 31003 .

[33] J. Ayache, L. Beaunier, J. Boumendil, G. Ehret, D. Laub, Guide de Preparation des Echantillons pour la Microscopie Electronique en Transmission-Tome II, Vol. II, Universite de Saint-Etienne, Saint-Etienne, 2007.

[34] K. R. Lee, S. H. Choi, J. Kim, H. W. Lee, J. H. Lee, J. Power Sources 2005, 140, 226.

[35] K. Thydén, Y. L. Liu, J. B. B.-Soerensen, Solid State Ionics 2008, 178, 1984.

[36] J. Russ, The Image Processing Handbook, CRC Press, Boca Raton, 1992, 224 pp.

[37] H. Heijmans, Morphological Image Operators, Vol. 25, Advances in Electronics and Electron Physics, Academic Press, San Diego, 1994, 55 pp.

[38] E. Underwood, Quantitative Stereology, Addison-Wesley Publishing, Menlo Park, 1970.

[39] M. I. Mendelson, J. Am. Ceram. Soc. 1969, 52, 443.

[40] ASTM E 112-63, Vol. 31, American Society for Testing Materials, Philadelphia, 1967, 446 pp.

[41] J. Serra, Image Analysis and Mathematical Morphology, Academic Press Limited, San Diego, 1982.

[42] C. Giardina, E. Dougherty, Morphological Methods in Image and Signal Processing, Prentice-Hall, Englewood Cliffs, New Jersey, 1988, 97 pp.

[43] P. Bowen, J. Dispersion Sci. Technol. 2005, 23, 631.

[44] S. Brunauer, P. H. Emmett, E. Teller, J. Am. Chem. Soc. 1938, 60, 309.

[45] M. N. Rahaman, Sintering of Ceramics, CRC Press, Boca Raton, 2008.

[46] G. Froment, K. Bischo, Chemical Reactor Analysis and Design, 2nd Ed., Wiley, New York, 1990.

[47] S. P. Jiang, S. H. Chan, J. Mater. Sci. 2004, 39, 4405.

[48] J. R. Wilson, W. Kobsiriphat, R. Mendoza, H. Y. Chen, J. M. Hiller, D. J. Miller, K. Thornton, P. W. Voorhees, S. B. Adler, S. A. Barnett, Nat. Mater. 2006, 5, 541.

[49] J. O. M. Bockris, A. K. M. Reddy, M. G.-Aldeco, Modern Electrochemistry, Kluwer Academic and Plenum Press, New York, 2000.

[50] C. G. Vayenas, M. M. Jaksic, S. Bebelis, S. G. Neophytides, in: Modern Aspect of Electrochemistry, (Eds.: J. O. M. Bockris, B. E. Conway, R. E. White), Kluwer Academic and Plenum Press, New York, 1996.

[51] S. Tao, J. T. S. Irvine, Chem. Rec. 2004, 4, 83.

[52] P. Tanasini, A. Faes, P. Costamana, M. Cannarozzo, A. H.-Wyser, J. Van herle, C. Comninellis, Fuel Cells 2009, this issue.

[53] CRC Handbook of Chemistry and Physics, 53rd Ed., CRC Press, Cleveland, 1973, pp. B-114. 